\title{
Benign and Malignant Disease Caused by EBV
}

\author{
Hans Wolf, M.D., Ph.D., and Rudolf Seibl \\ Max von Pettenkofer-Institute for Hygiene and Medical Microbiology, University of Munich, Munich, Western (iermany
}

\begin{abstract}
Epstein-Barr virus (EBV) causes infectious mononucleosis as a primary disease. The virus infects more than $\mathbf{9 0 \%}$ of the average population and persists lifelong in peripheral B-lymphocytes. The virus is produced in the parotid gland and spread via the oral route. Serology suggests that the Epstein-Barr virus might be involved in the causation of two neoplastic diseases of humans: African Burkitt's lymphoma and nasopharyngeal carcinoma. Whereas the development of the lymphoma has an even better linkage with chromosomal rearrangements, nasopharyngeal carcinoma shows a unique association with Epstein-Barr virus. Environmental factors, including traditional Chinese medicine, may be responsible for the enhanced risk of nasopharyngeal carcinoma in certain, predominantly Chinese, populations of southern Asia. Possible mechanisms leading to the estabiishment of the neoplastic manifestations will be discussed.
\end{abstract}

Epstein-Barr virus (EBV), papilloma virus, and hepatitis B virus have a few remarkable properties in common. Their mobile nucleic acid is DNA that is circular or integrated during latency, they persist lifelong in carriers, and they resisted all attempts to grow them in vitro in a simple and fully lytic system. They are, however, efficiently transmitted in nature, where they may cause a more or less severe primary infection followed by a lifelong carrier status, indicating the delicate interaction of these viruses with their hosts. $\mathrm{EBV}^{*}$ was first isolated and characterized as a herpes group virus from lymphoblastoid cell lines of the B lineage established from African Burkitt's lymphomas (BL). Viral particles or structural antigens have never been detected in fresh biopsies. The possibility to grow these cell lines from the neoplastic tissue was not only technically very helpful, because these cells could be used as an antigen source for serologic studies, but it was also supposed to be a significant observation as far as the mechanisms of oncogenicity are concerned. The role of EBV in this process was stressed by the fact that B cells of normal umbilical cord blood are efficiently immortalized by preparations of EBV. When some years after these initial findings marmosets died of lymphoproliferative disease after inoculation with EBV, it appeared as if the Henle-Koch postulates for the causation of a neoplastic disease of humans by a virus had been fulfilled for the first time.

However, if one looks to the Henle-Koch postulates in their original version with all their limitations, especially for assessing secondary or chronic disease, one can see that the situation

Reprint requests to: Dr. Hans Wolf, Max von Pettenkofer-Institut, Pettenkoferstrasse 9a, 8000 Munich 2, West Germany.

Abbreviations:

BL: Burkitt's lymphoma

EA: early antigens

EBNA: Epstein-Barr nuclear antigen

EBV: Epstein-Barr virus

NPC: nasopharyngeal carcinoma

PBL: peripheral blood lymphocyte

TC: Tonsillar carcinoma

VCA: Viral capsid antigens

* Most of the data presented in the first part of this paper are extensively referenced in available review literature [1-3]. should not be seen as simplistic. The Henle-Koch postulates (in a translation of Rivers [4]) are as follows:

1. The parasite occurs in every case of the disease in question and under circumstances that can account for the pathologic changes and clinical course of the disease.

2. It occurs in no other disease as a fortuitous and nonpathogenic parasite.

3. After being fully isolated from the body and repeatedly grown in pure culture, it can induce the disease anew.

For African BL, the first postulate is not fulfilled in only $3 \%$ of cases. However, clinically very similar lymphomas outside Africa-where they are much rarer-can be associated with EBV in only $25 \%$ of cases. This will be commented on later. The second postulate is not exactly fulfilled because EBV is regularly associated with infectious mononucleosis, clinically inapparent seroconversion and nasopharyngeal carcinoma. The third postulate is also not fulfilled in its strict sense because the experimentally infected marmosets present with a polyclonal, although fatal, lymphoproliferative disease. This observation will also be commented on later.

\section{SEROLOGY OF EBV-RELATED DISEASES}

The B-cell lines that can be established from BL or, as was shown later, from anybody's peripheral blood leukocytes after primary EBV infection vary in their ability to produce virus, although every single cell contains EBV genomes and expresses a nuclear antigen, EBNA. Some cell lines, e.g., one named Raji, can be treated with a variety of chemicals, such as IUDR, butyric acid, phorbol esters, or cycloleucine. All these compounds are inhibitors of DNA-methylation and induce synthesis of additional virus-related antigens that have been named early antigens (EA). Only few cell lines stably produce virus and viral capsid antigens (VCA) by spontaneous activation of the latent genome in a characteristic fraction of the cells. The various cell lines proved of tremendous value for molecular biology and seroepidemiology. Using these antigens, the Henles and a number of other investigators found that $\mathrm{BL}$ patients had invariably high antibody levels to EBV-related antigens. The seroconversion to EBV positivity of one laboratory technician following severe mononucleosis was the initiator of a study with college students at Yale that clearly showed that $\mathrm{EBV}$ is the cause of infectious mononucleosis and that this frequent disease of higher socioeconomic groups is the primary disease caused by EBV.

Sera from nasopharyngeal carcinoma revealed similar EBV specific antibody patterns to those observed for BL. Sera from a variety of other diseases (Hodgkin's disease, chronic lym phatic leukemia, chronic myelon leukemia, and sarcoidosis, just to name some) also showed significantly elevated antibod. titers. However, in all these cases, a significant fraction of sera was negative and antibody levels to other latent viruses (vari cella virus, cytomegalovirus) were also elevated.

\section{INFECTIOUS MONONUCLEOSIS AS THE PRIMARY DISEASE CAUSED BY EBV}

Infectious mononucleosis seems to be unknown in such areas as the Philippines [5] or Malaysia [6], where infection by EBV occurs very early in life and almost everybody has antibodies 

by he age of 10 years. Clinical symptoms seem to be a consequ nce of juvenile or adult infection, and one might speculate wh ther a vaccine-primed organism will be infected without ses sre clinical symptoms.

'he clinical diagnosis of infectious mononucleosis is usually dei ived from a combination of four signs:

High leukocyte count ranging from 10,000 to 20,000 and reaching up to 50,000

$10 \%$ atypical cells

$\therefore$ Lymphadenitis

4. Fever

The most frequent symptoms are listed in Table I.

TABLE I. Clinical symptoms of infectious mononucleosis

\begin{tabular}{lc}
\multicolumn{1}{c}{ Symptom } & Incidence \\
\hline Enlarged lymph nodes & $80-100 \%$ \\
Fever & $85-98 \%$ \\
Pharyngitis & $80-95 \%$ \\
Tonsillitis & $90-98 \%$ \\
Splenomegaly & $40-90 \%$ \\
Hepatomegaly & $30-40 \%$ \\
Periorbital edema & $10-30 \%$ \\
Enanthema & $30-50 \%$ \\
Exanthema & $3-15 \%$ \\
Jaundice & $5-10 \%$
\end{tabular}

Source: Modified from [7].

TABLE II. Complications of EBV infection

1. Hematologic: Agranulocytosis, granulocytopenia, autoimmunohemolytic anemia, thrombocytopenia, panmyelopathy

2. Hepatic: Hepatitis, massive necroses

3. Neurologic: Cerebellitis, encephalitis, Guillain-Barré syndrome, meningoencephalitis, transverse myelitis, SSPE

4. Renal: Glomerulonephritis, nephrotic syndrome

5. Cardiovascular: Myocarditis, pericarditis

6. Respiratory: Acute laryngitis, interstitial pneumonia, bronchopneumonia

7. Others: Arthritis, dermatitis, splenic rupture, immunodeficiency, myoglobinuria, subacute thyroiditis, transitory anergia

8. Neoplastic: Conversion of polyclonal B-cell proliferation to monoclonal B-lymphoblast malignancy
Several authors described a much higher prevalence of rash. This is, however, in most cases due to a typical concomitant hypersensitivity to ampicillin. About 1 percent of the infectious mononucleosis cases show one or more of the complications listed in Table II, either already at the onset of the disease or as a late consequence. Most complications are due to autoimmune mechanisms and are in some cases indiscernible from graft versus host disease, a mechanism by which the body could clear itself from the excess of EBV-converted proliferating B cells.

Under rare circumstances, the T-cell response might be insufficient because of temporary influences such as treatment with high doses of cyclosporin A in combination with corticosteroids or because of AIDS or a certain genetic predisposition as described by Purtilo et al (Duncan's syndrome, XLP, Xchromosome-linked lymphoproliferative disease) [9]. In these cases, occasional B cells have a chance to escape host control and grow without limitation, as they do when they are kept in vitro. The consequences have been described as BL-like disease in 3 AIDS patients [10] or as polyclonal lymphoproliferative disease for XLP patients [9] or kidney transplant recipients [11].

The first standard test for the diagnosis of infectious mononucleosis is still the test for heterophile antibodies when specific tests are not available. For young children, these tests are false negative in up to $30 \%$ of cases. EBV-specific antibodies

TABLE III. Serologic parameter associated with various disease conditions

\begin{tabular}{lrrrrrrr}
\hline \multirow{2}{*}{ Disease } & \multicolumn{3}{c}{ VCA } & EA & EBNA & MA $^{b}$ \\
\cline { 2 - 7 } & IgG & IgM & IgA & & & \\
\hline Normal adults & + & - & - & - & + & + \\
Acute adults (early) & ++ & + & - & + & - & - \\
Chronic infection & + & + & - & \pm & \pm & \pm \\
Reactivation & + & + & - & + & + & + \\
XLP & + & + & - & - & + & +() & $?$ \\
NPC & + & - & + & $+(D)$ & + & ++ \\
BL & + & - & - & $+(R)$ & + & + \\
\hline
\end{tabular}

${ }^{a}$ XLP as an example of immunologically deprived hosts.

${ }^{b}$ Determined by immunoprecipitation of GP 240/200.
FIG 1. In situ EBV DNA hybridization if cryosections of normal parotid gland $a, b)$, normal tonsil $(c)$, and nonkeratinzing tonsillar carcinoma $(d)$. Cloned IBV DNA that was labeled in vitro with "I] thymidine triphosphate by nick rinslation was used as a probe. Note 1 at the producing cells (arrow) in the ) rotid glands surround or are present $r$ the ducts $(a, b)$, that the normal tonsil s EBV-genome-free (c), and that the (nsillar carcinoma contains EBV-car? ing cells (arrow) $(d)$. (From Wolf et al :9].)
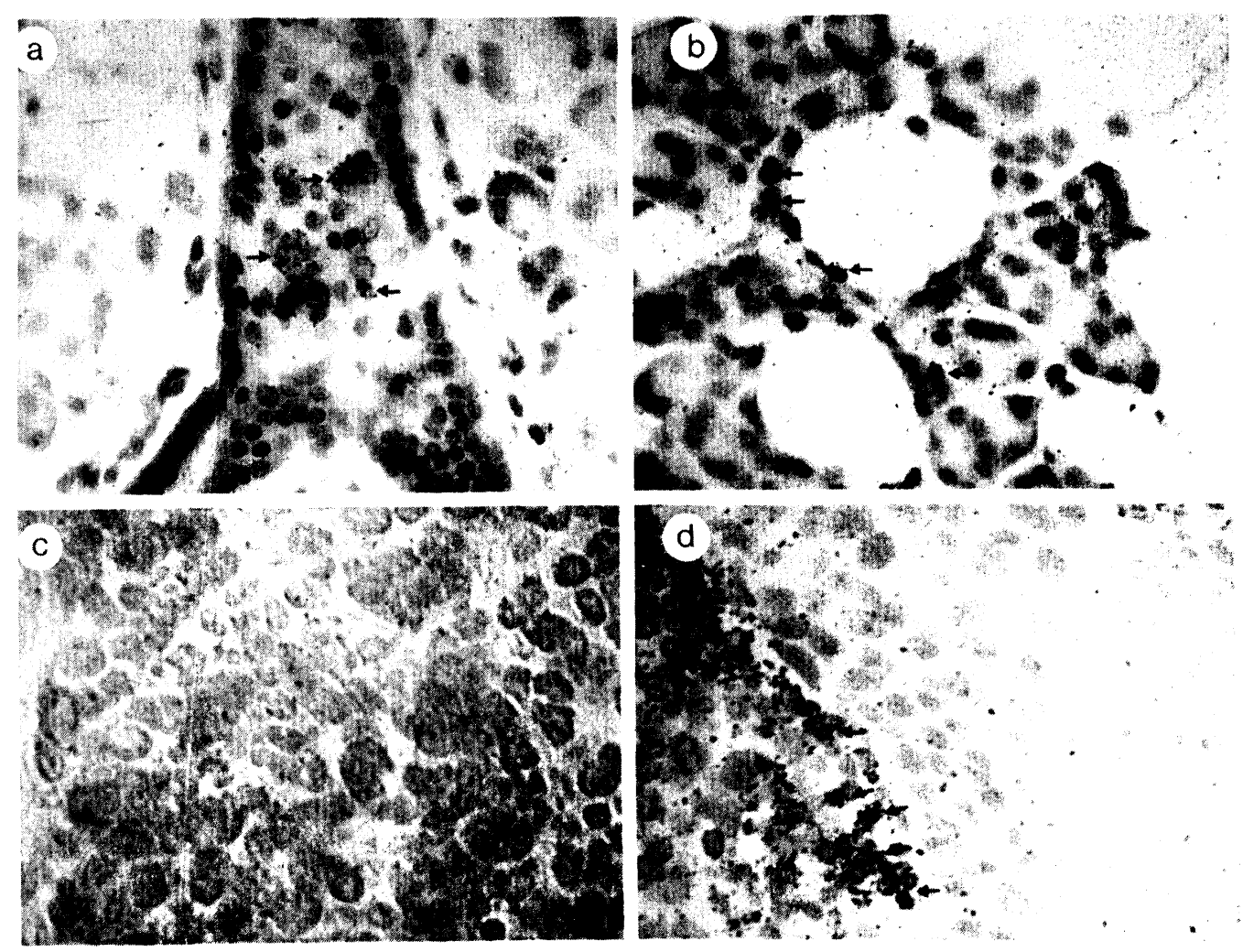
vary in their value for diagnosing disease. Table III gives the appearance and persistence of the antibodies with their respective reactivities.

There is no cure for infectious mononucleosis other than time, although the clinical symptoms and the antibody titers reportedly reach normal values much faster, especially in severe cases, when the tonsils are removed [12]. The tonsils may be the primary site of immunologic defense and the reservoir or "recruitment center" of B-lymphocytes able to proliferate. Following convalescence, about $0.01 \%$ of B cells supposedly contain EBV genomes or EBNA and are able to grow in vitro. The chances of growing EBV-immortalized B cells are higher if leukocyte preparations are infected with certain strains of EBV (e.g., from the B-95-8 marmoset cell line). When this in vitro immortalization is done with leukocyte preparations from EBV-immune individuals, the $\mathrm{T}$ cells have to be removed. At least $60 \%$ of patients with infectious mononucleosis shed EBV in their saliva. Virus shedding does not require special prevention against spreading the disease because epidemics are rare and infection of persons in close contact (roommates) is scarce [13]. Virus shedding does not stop with recovery from disease, and at least $30-40 \%$ of the adult population sheds EBV.

\section{NASOPHARYNGEAL CARCINOMA AS A POSSIBLE "SECONDARY DISEASE" RELATED TO EBV}

The other disease in which EBV so far shows a 100 percent association is nasopharyngeal carcinoma (NPC) [3]. NPC most frequently starts at the fossa rosenmuelleri at the postnasal space, although patients frequently report only after the first typical metastases in the cervical lymph nodes have developed. The disease has an incidence of up to 40 per 100,000 per year, the most frequent neoplasia of humans occurring in some areas of southern China and among Chinese in Singapore and Malaysia. The incidence is also elevated in other parts of the world, such as Borneo or Tunisia. In most other areas, the incidence is around 0.2 per 100,000 per year. The age distribution shows a clear single peak around the ages of 40 to 50 in almost all high-risk areas. There is, however, a second peak at an early age, ranging from 5 to 15 years in Borneo and to some extent in Tunisia [3]. Possible exogenous risk factors will be discussed later. A genetic disposition for the disease is difficult to test, although the decline of tumor incidence in secondgeneration Chinese emigrants to the United States, expecially if they live in rural areas, does not support a genetic involvement [1-3]. The relatively simple HLA patterns of the Chinese allowed, however, a significant association of relative risk with certain HLA types. A2 and BW46 have elevated relative risks of 1.5 and 1.9, respectively, and of 2.5 if expressed in combination, and B17/BW58 is associated with a relative risk of 2.2 . $\mathrm{A} 11$, however, is associated with a relative risk of 0.5 . Thus a relative risk factor of 5.0 exists between the best and the worst constellation of HLA types [14]. The neoplasia leads invariably to death of the patient, frequently with extensive cranial invasion unless the tumor is recognized early and treated. The most successful therapeutic approach is early detection combined with careful radiation [15], and survival rates exceeding $90 \%$ have been reported (Yi Zeng, personal communication). The use of inexpensive screening methods becomes evident in face of the correlation between a rapid decline in survival rates and the elapsed time between the putative earliest detection with careful screening and the actual detection of disease and first intervention. The determination of IgA anti-VCA antibodies has been used with good success to define a group at high risk, since $3 \%$ of persons positive in this test had NPC upon clinical examination. Between 35 and $70 \%$ of tumor bearers have IgA antibodies to EA; therefore, this test can be used with good success as a second screening step. About 30 percent of patients positive in the IgA anti-EA test have detectable NPC [43]. New and improved methods for the detection of viral nucleic acid and the development of sampling devices that aspirate cells without taking biopsy [16] may further improve the diagn sic possibilities. The introduction of single-stranded hybridization probes and the availability of label other than ${ }^{32} \mathrm{P}$ with its inhibitory short half-life have helped to bring nucleic acid hybridization over the threshold of a routinely usable method. Considering cost-effectiveness, necessary equipment, and sensitivity, we have found that chemical iodination of a collection of viral fragments cloned in the single-stranded DNA phage m13 gives excellent hybridization probes usable for in situ hybridization and hybridization on Southern blots of DNA or spotted DNA or cell lysates [44].

\section{BURKITT'S LYMPHOMA AND ITS ASSOCIATION WITH EBV}

Burkitt's lymphoma has been discussed earlier, and additional remarks will be found in the Discussion section.

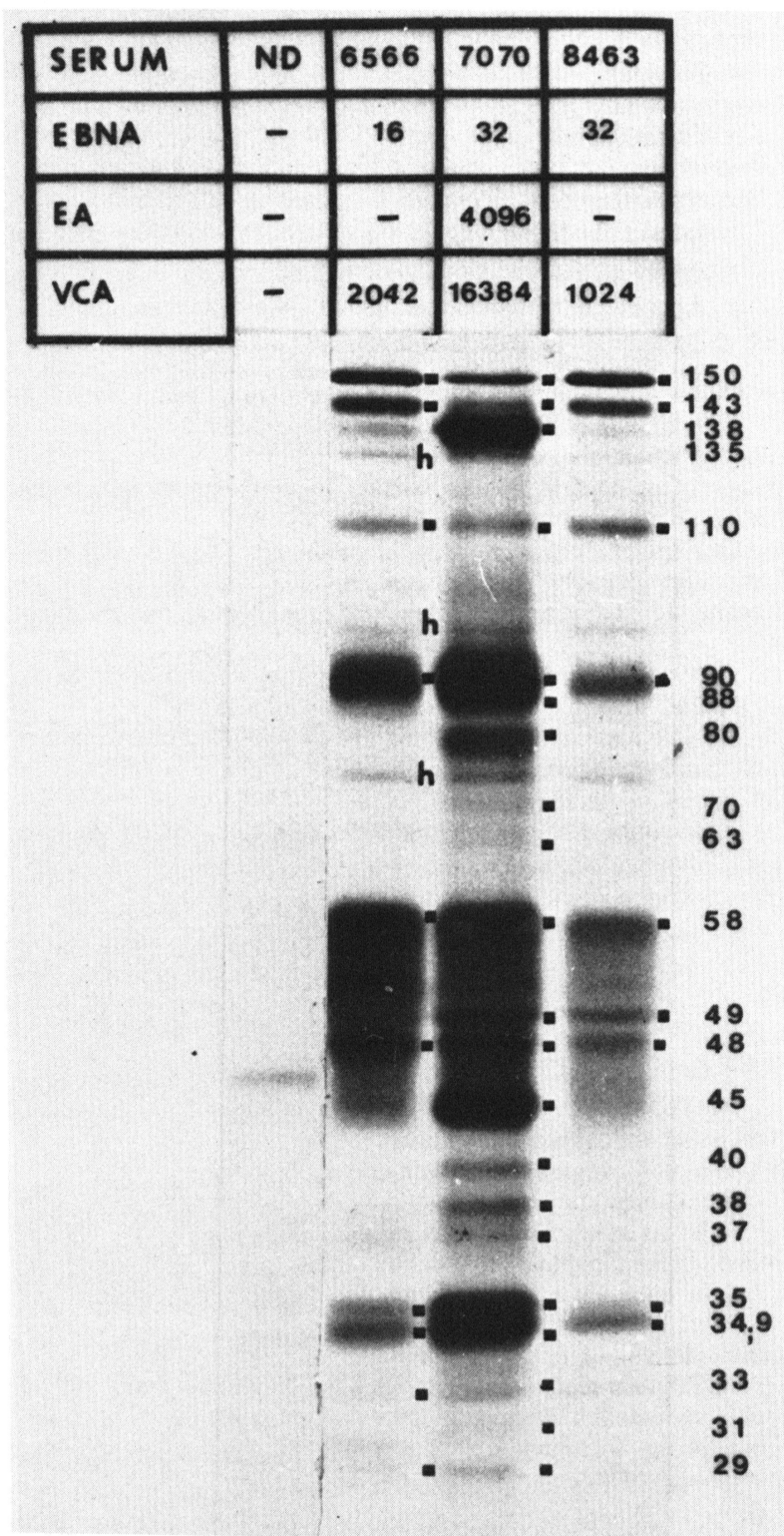

FIG 2. An analysis of EBV-specified polypeptides by immunopr cipitation using sera with different reactivities to EBV-specified an gens. ND is a serum free of EBV antibodies; 6966 and 8463 have his titers against VCA but not EA; serum 7070 has high titers against bo: VCA and EA. Proteins $138,88,45,40,38$, and 37 are only precipitat by the EA-positive sera. These results are representative for a mu larger panel of sera which we have tested. (From Bayliss and Wo [30].) 

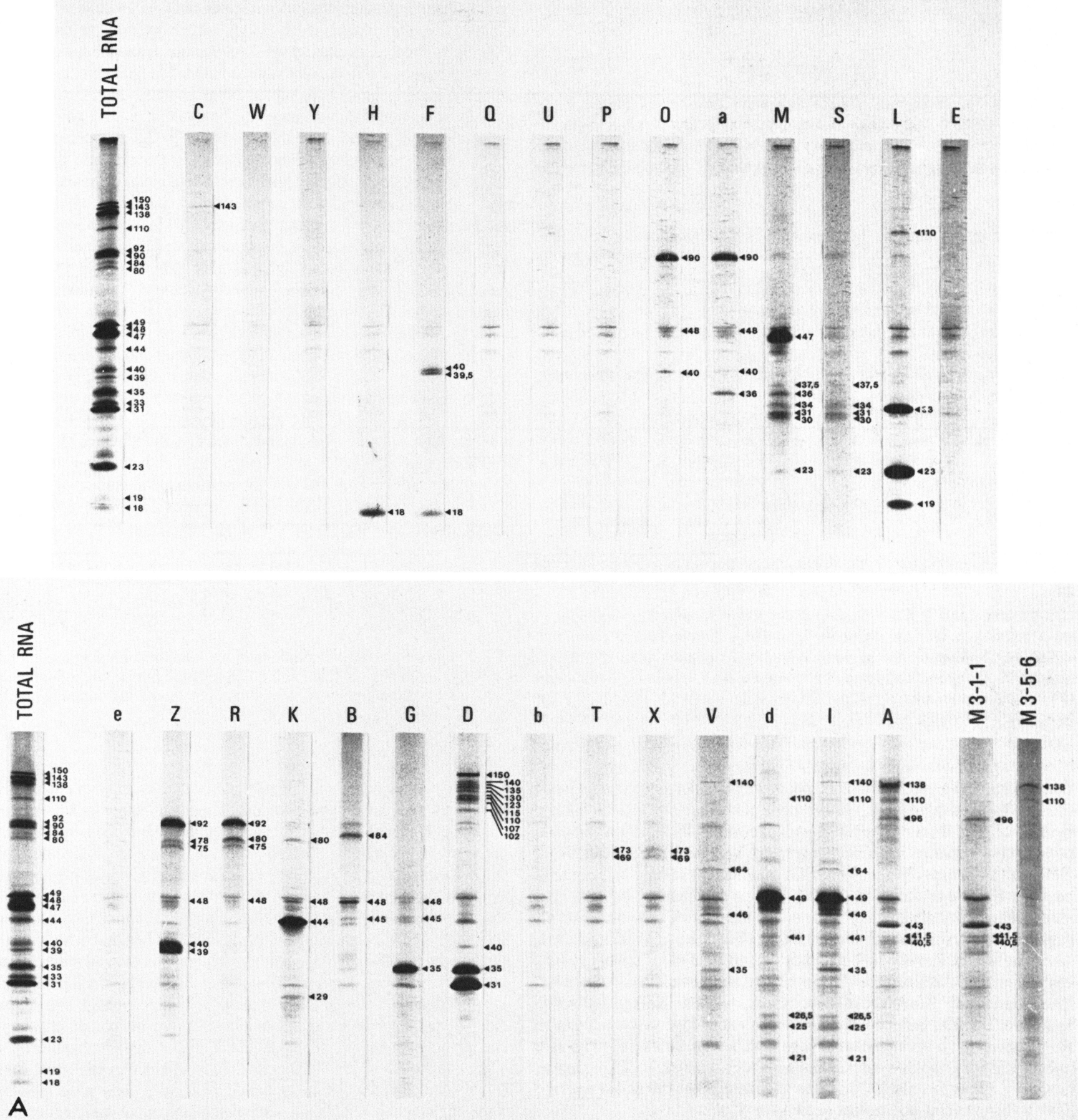

FIG 3. a, RNA from induced P3HR1 was hybridized to the cloned EBV Bam fragments and two clones (M 3-1-1 and M 3-5-6) that subdivide the BamA fragment (see map). The bound mRNA was eluted and translated in vitro using the rabbit reticulocyte system. The translation products were immunoprecipitated and analyzed on SDS-polyacrylamide gels.

\section{SOME OPEN PROBLEMS AND APPROACHES TO SOLVING THEM}

The presented observations on the involvement of EBV with leoplastic and nonneoplastic disease raised a number of questions that will be discussed in this section:

1. What is the source of virus in the throat washings of apparently healthy persons, and why do apparently normal individuals who shed virus have antibodies only to VCA and EBNA and not to EA, which are produced in large amounts during viral replication?
2. How does the virus infect epithelial cells that apparently lack receptors for the virus?

3 . How does the virus persist in cells lifelong, and what are the molecular mechanisms underlying the regulated expression of EBV?

1. One might postulate that EBV-carrying lymphocytes in the oropharynx that may have escaped host control mechanisms could be the source of the virus that can be obtained from healthy individuals. Other studies [17] indicated that EBV could be isolated in relatively high titers from saliva collected 


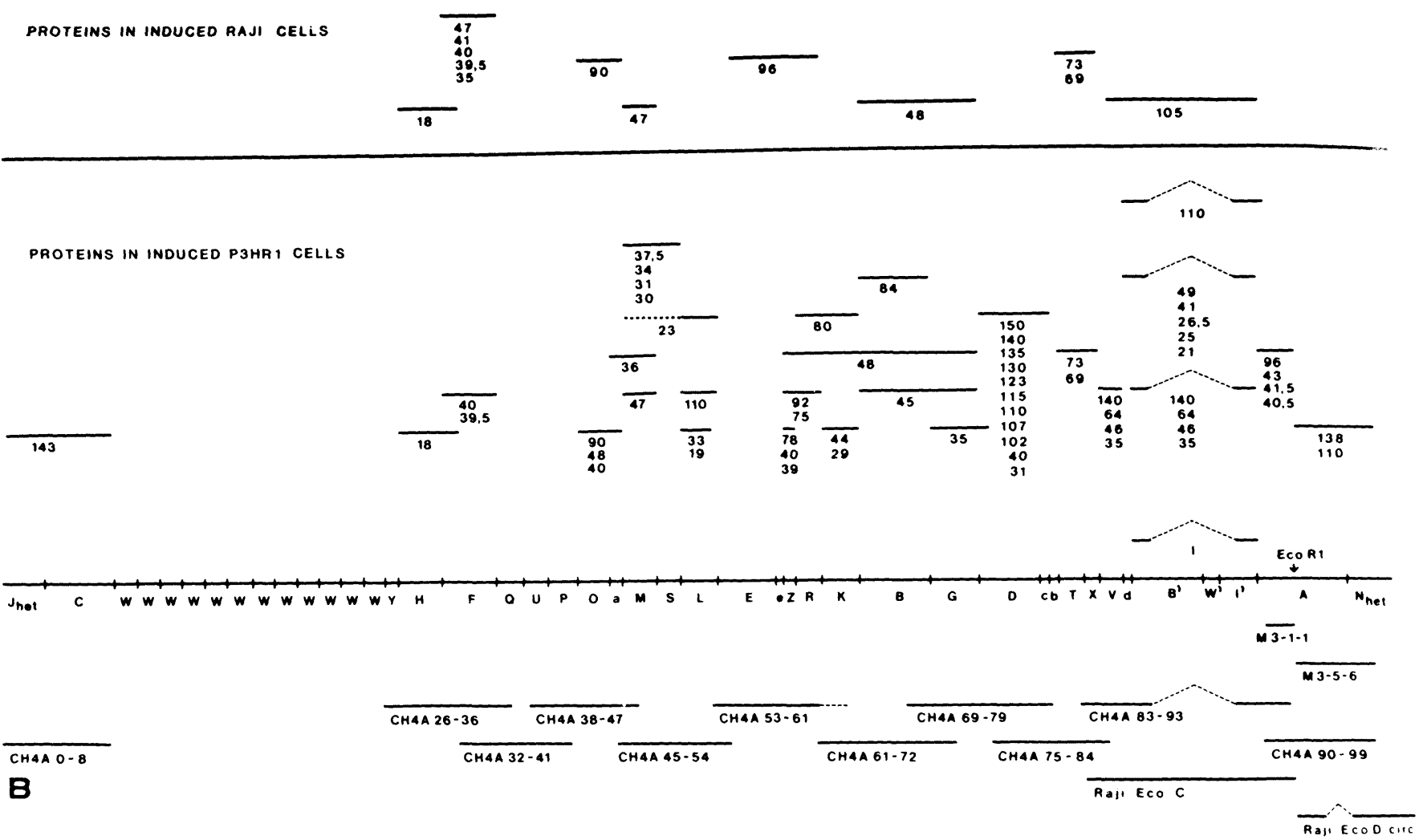

FIG 3. $\quad b$, Map of the in vitro translated proteins with hybrid-selected RNA from induced P3HR1 cells and induced Raji cells. The Bam fragments were cloned from B 95-8 derived EBV DNA. By hybridizing to sheared fragments of EBV DNA cloned in Charon 4A, a finer map of the coding regions of some proteins could be achieved. The narrow coding regions for proteins 18,90,47, 73, and 69 in the induced Raji cells are based on the assumption that these proteins correspond to proteins with the same molecular weights in P3HR1 cells.

from Stenson's duct. Studies on parotid salivary gland tissue $[18,19]$ have suggested that the cells which surround or fill the lumen of the ducts of this gland are capable of supporting a productive cycle of EBV replication (Fig 1, $a, b$ ). Production of EBV in salivary duct cells could also explain the absence of certain EBV-specific serum antibodies in normal adults (see also Discussion). Searches with other tissues of the oropharynx (e.g., tonsils from healthy individuals; Fig 1,c) proved negative, since no productively infected cell could be found using in situ hybridization techniques. This situation resembles somewhat that seen with Marek's disease virus, where the transformed cells are $T$ cells, but the lytic expression of the virus occurs in the germinative epithelium of the feather follicles [20]. In situ hybridization studies using tonsillar carcinoma (TC) tissue, however, showed that $25 \%$ of the specimens tested so far carried EBV DNA in the epithelial cells (Fig 1,d).

2. To date, receptors for $\mathrm{EBV}$ have been demonstrated only on B-lymphocytes [21] and no other normal nonmalignant cell type [3]. How then does the virus enter such cells and persist within them? Initially, microinjection of EBV DNA into a wide variety of receptor-negative cells [22] and, later, transfection with EBV DNA using the calcium phosphate coprecipitation technique $[23,24]$ and the implantation of receptors into the membranes of receptor-negative cells [25] have been used to demonstrate that once EBV overcomes the barrier of penetration, normal expression of the virus can occur, although synthesis of EBNA was not observed when only lytic expression was induced. It was proposed some time ago that syncitiuminducing viruses, such as paramyxovirus, might induce fusion between lymphocytes and epithelial cells, thus allowing the virus to gain access to such cells. Since then, we have demonstrated that EBV itself can induce fusion. When densely packed monolayers of lymphoblastoid cells [26] were infected with EBV derived from the EBV-producing cell line P3HR1, the formation of polykaryocytes could be observed. Further studies with mixed monolayers containing both receptor-positive (Raji) cells and receptor-negative cells (human fibroblasts, epithelial cells, or T-lymphoblastoid cells) showed that an infected EBVantigen-expressing B-lymphoblastoid cell was capable of fusing with a noninfected receptor-negative cell [27]. A close cell-tocell contact, such as occurs in monolayers, is necessary for the development of polykaryocytes. The viral nature of the fusion event and the mechanisms involved have been studied in detail using chemical activation of latent genomes and various metabolic inhibitors. It was shown that an early viral protein was responsible for the fusion event [28]. More recent experiments [29] have further substantiated the viral origin of the fusioninducing protein(s). Purified EBV DNA was transfected into unrelated cells (NIH 3T3 cells). In addition to the synthesis EBV EA, fusion of the transfected cells was also observet. Further studies with this technique using cloned fragments $f$ the EBV genome should permit the mapping of gene(s) enco. ing the fusion on the EBV genome [29].

3 . Very little is known at the molecular level of the mech nisms that regulate the response of the cell to infection w: EBV. As far as we know, all EBV-carrying cell lines expres: single viral antigen-EBNA. This protein could be the repr sor protein that prevents lytic expression. If EBV-carrying $c$ lines are infected with a sufficiently high multiplicity, a ly cycle will occur [30], during which at least 30 virus-induced specific proteins will be synthesized. These proteins can divided into three groups according to their kinetics of synt\} sis, response to inhibition of DNA synthesis, and requireme for virus-specified factors.

Do these observations have any relevance to regulat expression of EBV during the stepwise induction of a lytic cye by the virus in the absence of inhibitors? If Raji cells : infected with decreasing amounts of virus, then the interm diate and late proteins are no longer synthesized at a cert: cutoff value $[29,31]$. 
However, a certain subset of the EA complex is made, and it is the same subset as that obtained by chemically induced Raji ctlls. Similar observations have been made using an EBV genome-negative cell line (BJA). Immunoprecipitation of EBV $\mathrm{p}$ oteins allows further characterization and a linkage to serolo gic data. These data (Fig 2) show also that proteins of the EA complex are synthesized in considerable amounts during the replication of EBV; yet normal adults do not have antibodies against these proteins even if they shed virus.

In an attempt to substantiate further the viral nature of the polypeptides and to map the genes on the viral genome, both of which are essential for detailed studies of the molecular basis for regulation of viral gene expression, we selected mRNA from a producer cell line (P3HR1) by hybridization to cloned EBV DNA fragments. This mRNA was then translated in vitro using a rabbit reticulocyte translation system. With this technique we were able to identify proteins as EBV-specific and have mapped their positions on the EBV genome (Fig 3, $a, b$ ) (Rudolf Seibl and Hans Wolf, in preparation).

One interesting observation that awaits explanation is that if mRNA from EBV-negative cells (BJA-B) is selected using EBV DNA, an mRNA is obtained that hybridizes to the BamHI $\mathrm{K}$ fragment of the EBV genome. This RNA can be translated in vitro to yield polypeptides of $84 \mathrm{kd}$ and $92 \mathrm{kd}$ molecular weight (Fig 4). This region of the EBV genome is known to hybridize to cellular DNA under stringent conditions and may

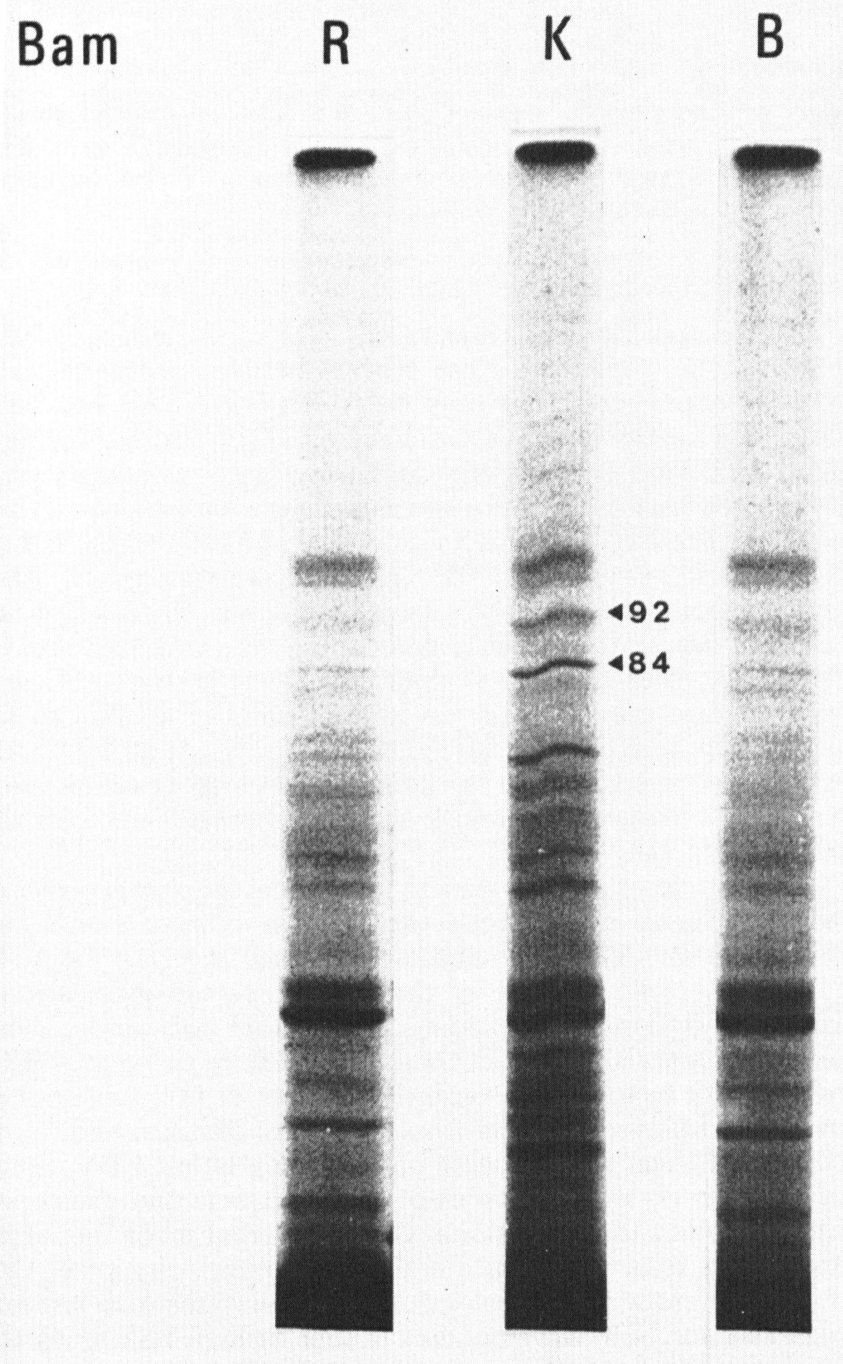

FIG 4. RNA from BJA-B cells was hybridized to cloned Bam fragments of EBV as given on top of the gel slots. The bound mRNA was eluted and translated in vitro. Translation products were analyzed on SDS-polyacrylamide gels. represent cellular sequences that have been incorporated into the viral genome during the course of evolution.

\section{DISCUSSION}

A model has been developed that attempts to include the available data and should be useful to predict certain events or measurable parameters as well as to design further experiments, thus allowing the hypothesis to be further tested (Fig 5).

\section{Normal Situation}

a. Primary infection: Development of antibodies to VCA, EA, and EBNA

As suggested, EBV infects B-lymphocytes during acute or primary infection, and because of the lack of immune response, a number of cells enter into the lytic cycle and produce a full set of viral antigens (EA and VCA) that are shed into the bloodstream. It seems probable that not all B-lymphocytes are capable of supporting a fully lytic infection because of a cellular factor that prevents expression of EBV (Fig 5, block 2). These cells will be selected for and grow on to become the cells that carry EBV latently for the rest of the host's life.

Because of the release of all the EBV-specified antigens, antibodies will be developed against EA, VCA, and EBNA (Table III).

b. Convalescence: Disappearance of antibodies to EA and maintenance of antibodies to VCA and EBNA

As the immune defense mechanisms of the body remove the lytically infected cells from the circulation (Fig 5 , block 2), the antibody levels will start to fall during the convalescent phase. After a certain period, antibodies to the EA disappear. However, as mentioned above, EBV is produced in the parotid gland. The viral particles and intracellular virus-associated antigens including EA will be shed into the saliva and reach the oropharynx. Here the viral particles (but not EA) could bind to the Blymphocytes and be presented to the body as antigens, thus maintaining the antibody titers to VCA. EA cannot bind to the lymphocytes and will be degraded by proteases and not be available to the body as antigens. Circulating lymphocytes that carry EBV latently contain EBNA and as far as we know no other EBV-specified protein. These lymphocytes will be subject to the normal turnover processes, and as they die, they will release EBNA into the bloodstream. Therefore, antibodies to this antigen will persist. As a consequence, normal convalescent sera will have low-level IgG anti-VCA and anti-EBNA antibodies (Table III).

\section{Special Conditions}

a. Nonspecific secondary antibody titer increase to VCA and EA

If immunosuppression occurs, either because of other disease (e.g., Hodgkin's disease) or because of immunosuppressive therapy, some of the circulating peripheral blood lymphocytes (PBLs) will escape the normally tight control mechanism and enter into a cycle of virus replication, causing a secondary increase in the titers to EA, VCA, and EBNA.

\section{b. Development of Burkitt's lymphoma (monoclonal disease)}

Under rare circumstances, a cell clone that differs in its antigenic makeup may arise and be selected. This clone may then lead to the development of BL. Environmental mutagens [32] and unspecific "mitogens" (malaria) [33] that facilitate clonal selection through proliferation may favor this event. Specific karotypes in the selected clones may correlate to the altered antigenic makeup of these cells.

Following original observations by Manolova et al [34], several authors have indicated that chromosomal rearrangements occur in all BL cases independent of their association with EBV [35]. The most important step seems to be a translocation 


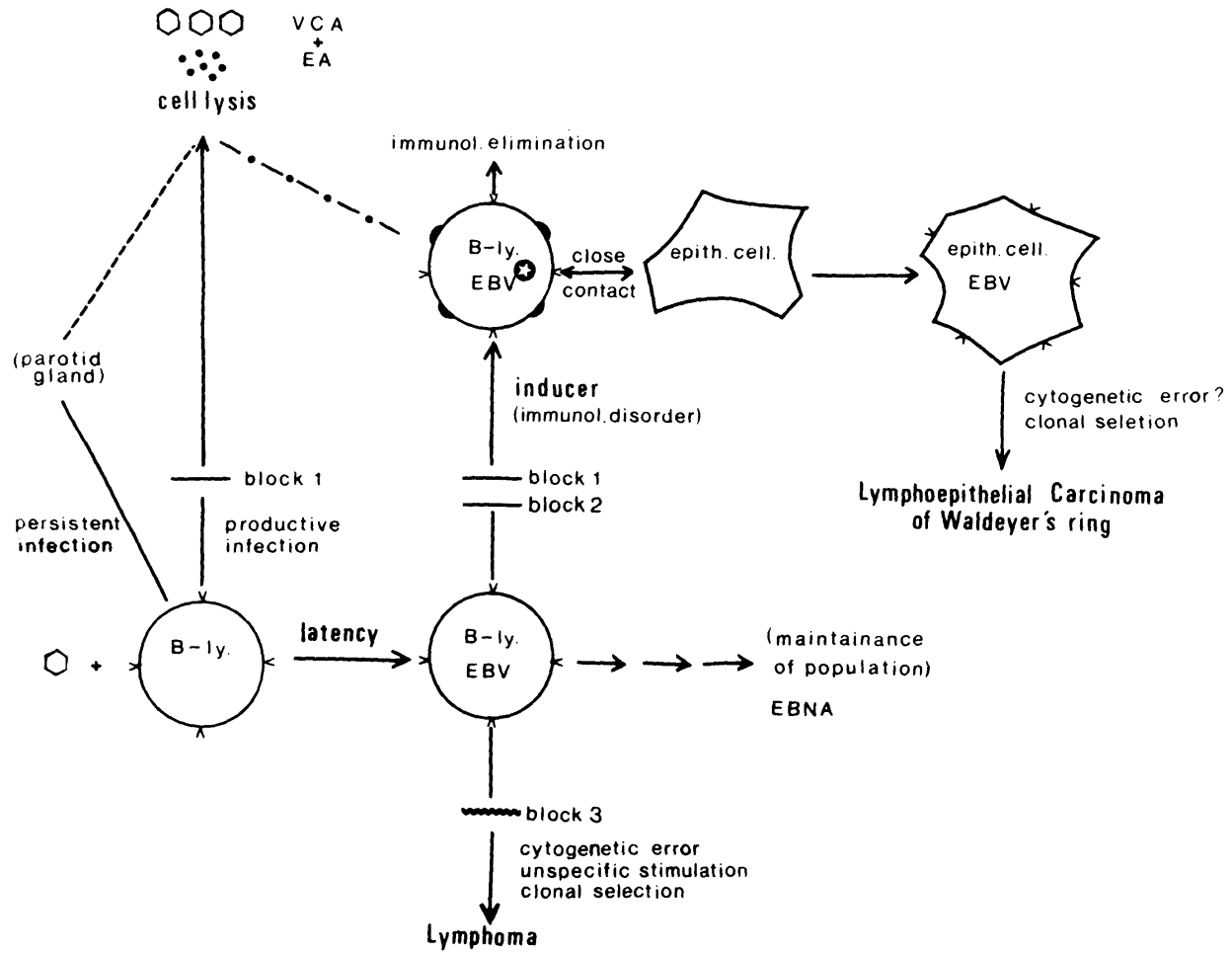

FIG 5. The scheme summarizes the suggested biological effects of EBV described in the text. Blocks 1 and 2 inhibit the lytic expression of EBV, and block 3 suppresses the proliferation of EBV genome containing lymphoid cells in the periphery. Block 1, Block at cellular level (endogenous block). Evidence: Only a certain percentage of cells from cloned cell lines produce virus. This block is responsible for poor production of virus. Block 2, Block from the outside (exogenous block, immunologic control?). Evidence: In peripheral blood from patients with infectious mononucleosis, in fresh BL or NPC biopsies no viral particles can be found. After explantation into tissue culture, a few cells start to produce virus. $\mathrm{O}: \mathrm{EBV}, \boldsymbol{\bullet}$ : activated $\mathrm{EBV}$ genes, v: EBV receptors, 0 : virus-specific changes. (From Wolf et al [29].)

of part of the distal arm of chromosome 8 carrying the cellular oncogene myc to alternate acceptor chromosomes 2,14 , or 22 , respectively. The oncogene is in all cases translocated to a transcriptionally active site close to immunoglobulin genes. Whether the transcription of the myc gene after translocation is enhanced and what impact this may have are not clear yet $[36,37]$. In any case, the involvement of myc alone cannot explain the patterns or mechanisms of appearance of BL.

It should be noted that all EBV genomes containing $\mathrm{B}$ lymphoblastoid cells have unlimited growth potential in vitro and after intracerebral injection into nude mice. Only the lymphoma-derived cells, however, can grow in the nude mouse after subcutaneous application [3]. This behavior seems rather suggestive of a loss of control elements on the surfaces of the selected clones. One might speculate that HLA or similar determinants are altered or lost during the process of clonal selection.

Transfection experiments have shown that two oncogenes frequently may be involved in oncogenesis [38]. Such a model could include an EBV gene as a possible member of a complementation group of oncogenes and $m y c$ as a member of another group. Thus EBV might still play a major role in the causation of African BL.

\section{c. Development of polyclonal proliferative disease}

Specific genetic constellations (XLP) or acquired conditions (immunosuppressed transplant recipients, AIDS patients; see above) determine a reduced efficiency of block 3 (cellular response to proliferating cells). Therefore, the selective pressure on peripheral B-lymphocytes (which already have a potential for unlimited growth by virtue of the resident EBV genomes) may be weaker. Under less stringent selective pressure, more cells may proliferate in vivo and lead to a polyclonal lymphoma [9]. Nonspecific growth stimuli such as the graft may favor initial proliferation and facilitate the selection of cell clones. A specific cytogenetic error [39] may occur under therapy and may induce a change from polyclonality to monoclonality.

\section{d. Relation to T-cell leukemia}

As a side effect of primary EBV infection, the initial proliferation of B-lymphocytes due to the early absence of block 2 apparently leads to a proliferation of T-lymphocytes [8]. This may well be caused by growth factors. This polyclonal activation of T-lymphocytes may occasionally activate $\mathrm{T}$ cells with malignant growth potential and lead to a T-cell leukemia following infectious mononucleosis.

\section{e. Development of nasopharyngeal carcinoma}

On the specific conditions of the site of initiation of lymphoepithelial tumors. A close contact between epithelial cells and B-lymphocytes that may carry EBV genomes has been described for the lymphoepithelial ring of the throat (Waldeyer's ring). This unique tissue may provide the necessary conditions for EBV-induced fusion between the two cell types, thus enabling the EBV genome to enter the epithelial cells. If this hypothesis is true, then EBV should be associated with other tumors that arise within this tissue. Evidence for this association has been independently derived by our group [28] and by Brichacek et al [40]. The major difference between TC and NPC is that only $25 \%$ of the limited number of TCs so far tested were serologically related to EBV, whereas all NPCs are EBV-genome-positive. At the moment, we cannot explain these findings. This proposal would be in good agreement with the proffered model.

On the role of environmental factors on the relative risk of NPC. It has been observed that certain plant extracts car induce latent EBV and somehow increase the risk for NP( [41]. Croton oil was one of the first suspected medications However, it is highly irritating and is used only under close medical supervision and is therefore unlikely to be an NPC related risk factor. More recently, Zeng et al [42] have teste: over 500 different extracts from 100 plant families and foun that 20 of them were capable of activating latent EBV. Som of the extracts were active as aqueous extracts and thus opes the possibility that traditional Chinese herbal medicine, ofte: applied as teas, may contain EBV-inducing principles. On difference in the EBV serology of the populations with low an high risk for NPC development is that in high-risk areas th level of antibody to EBV antigens remains high throughout lif when compared with low-risk populations (Yi Zeng and Sh Yan Gu, personal communication). Thus EBV-activating sub stances could continuously stimulate the latently infected I cells to enter into a lytic cycle, explaining the differences i: 
a itibody titers. If follow-up studies could demonstrate a match $b$ :tween the areas with high risk for NPC and the use of the $\mathrm{d}$ scussed plant extracts, a multifactorial causation of NPC и ould be substantiated.

\section{REFERENCES}

1. The Epstein-Barr Virus. Edited by MA Epstein, BG Achong. Berlin, Springer Verlag, 1979

2. Viral Oncology. Edited by G Klein. New York, Raven Press, 1980, pp 1-842

3. The Biology of Nasopharyngeal Carcinoma. UICC Technical Report Series, Vol. 71. Edited by M.J Simons, K Shanmugaratnam. Geneva, International Union Against Cancer, 1982, pp 1-87

4. Rivers TM: Viruses and Koch's postulates. J Bacteriol 33:1-10, 1937

5. Evans AS, Niederman JC: The Epstein-Barr virus. (Submitted for publication)

6. Tan DSK: "Absence" of infectious mononucleosis among Asians in Malaysia. Med .J Malaysia 21:358, 1967

7. Wahlen W, Ortgiese H.J, Kirsch W: Infektiöse Monokleose und Epstein-Barr Virus-Infektion im Kindesalter. Z Allg Med 55:1911, 1979

8. Purtilo DT: Immunopathology of infectious mononucleosis and other complications of Epstein-Barr virus infections, Pathology Annual, part 1, vol. 15. Edited by SC Sommers, PP Rosen. New York, Appleton-Century-Crofts, 1980, pp 253-299

9. Purtilo DT, Sakamoto K, Barnabei V, Seeley J, Bechtold T, Rogers G, Yetz J, Harada S, and the XLP Collaborators: Epstein-Barr virus-induced diseases in boys with the $\mathrm{X}$-linked lymphoproliferative syndrome (XLP). Update on studies of the registry. Am J Med 7:3:49-56, 1982

10. Ziegler JL, Miner RC, Rosenbaum E, Lennette ET, Shillitoe E, Casavant C, Drew WL, Mintz L, Gershow J, Greenspan J, Beckstead IJ Yamamoto K: Outbreak of Burkitt's-like lymphoma in homosexual men. Lancet 2:631-633, 1982

11. Hanto DW, Frizzera G, Purtilo DT, Sakamoto K, Sullivan JL Saemundsen AK, Klein G, Simmons RL, Najarian JS: Clinical spectrum of lymphoproliferative disorders in renal transplant recipients and evidence for the role of Epstein-Barr virus. Cancer Res 41:425:3-4261, 1981

12. Sauerbrei A, Sprössig M, Wutzler P, Färber I, Schweitzer H, Swoboda R, Wilke J: Antikörpertiterverlauf gegen Epstein-BarrVirus-spezifische Antigene bei infektiöser Mononukleose mit Tonsillektomie in der akuten Krankheitsphase. Laryngol Rhinol Otol (Stuttg) 62, 1983

13. Evans AS: The transmission of EB viral infections, Viral Infections in Oral Medicine. Edited by J Hooks, G Jordan. Amsterdam, Elsevier/North-Holand 1982, p 211

14. Chan SH, Day NE, Kunaratnam N, Chia KB, Simons MJ: HLA and nasopharyngeal carcinoma in Chinese: A further study. Int J Cancer 32:1711, 1983

15. Ho J: Treatment of Cancer. Edited by KG Halnan. London, Chapman and Hall 1982, pp 249-267

16. Richter W, Gu SY, Seibl R, Wolf H: A new method for examination of carcinomas of the nasopharynx, Nasopharyngeal Carcinoma: Current Concepts. Edited by U Prasad, DV Ablashi, P Levine, G Pearson. In press

17. Morgan DG, Miller G, Niedermann JC, Smith HW, Dowalby JM: Site of Epstein-Barr virus replication in the oropharynx. Lancet $1: 1154-1155,1979$

18. Wolf H, Wilmes E, Bayliss GJ: Epstein-Barr virus: Its site of persistence and its role in the development of carcinomas. Haematol Blood Transfusion 26:191-196, 1981

19. Wolf H, Bayliss GJ, Wilmes E: Biological properties of EpsteinBarr virus, Cancer Campaign, vol 5: Nasopharyngeal Carcinoma. Edited by E Grundmann. Stuttgart, Gustav Fischer Verlag, 1981, pp 101-109

20. Calnek BW, Hitchner GB: Localization of viral antigen in chickens infected with Marek's disease herpesvirus. J Natl Cancer Inst 43:935-949, 1969
21. Jondal M, Klein G: Surface markers on human B and T lymphocytes: II. Presence of Epstein-Barr virus receptors on B lymphocytes. J Exp Med 138:1365-1378, 1973

22. Graessmann A, Wolf H, Bornkamm GW: Expression of EpsteinBarr virus genes in different cell types after microinjection of viral DNA. Proc Natl Acad Sci USA 77:433-436, 1980

23. Stoerker J, Parris D, Yajima Y, Glaser R: Pleiotropic expression of Epstein-Barr virus in mouse lymphocytes. Proc Natl Acad Sc USA 78:5852-5855, 1981

24. Miller G, Grogran E, Heston L, Robinson I, Smith D: EpsteinBarr viral DNA: Infectivity for human placental cells. Science 212:452-455, 1981

25. Volsky KJ, Klein G, Volsky B, Shapiro IM: Production of infectious Epstein-Barr virus in mouse lymphocytes. Nature 293:299-401, 1981

26. Bayliss GJ, Wolf $\mathrm{H}$ : The spontaneous and induced synthesis of Epstein-Barr virus antigens in Raji cells immobilized on surfaces coated with antilymphocyte globulin. J Gen Virol 54:397-401, 1981

27. Bayliss GJ, Wolf $\mathrm{H}$ : Epstein-Barr virus induced cell fusion. Nature 287:164-165, 1980

28. Bayliss GJ, Wolf $\mathrm{H}$ : An Epstein-Barr virus early protein induces cell fusion. Proc Natl Acad Sci USA 78:7162-7165, 1981

29. Wolf H, Bayliss GJ, Seibl R: New results on the biology of EpsteinBarr virus. Current Topics in Veterinary Medicine and Animal Sciences. Edited by G Willmann, A Rziha, R Geskell, M Nijhoff. In press

30. Bayliss GJ, Wolf $\mathrm{H}$ : The regulated expression of Epstein-Barr virus: III. Proteins specified by EBV during the lytic cycle. J Gen Virol 56:105-118, 1981

31. Kallin B, Klein G: Epstein-Barr virus carried by Raji cells: A mutant in early functions? Intervirology 19:47-51, 1983

32. Birnboim HC: DNA strand breakage in human leukocytes exposed to a tumor promotor phorbol myristate acetate. Science 215:1247-1249, 1982

33. Burkitt DP: Etiology of Burkitt's lymphoma: An alternative hypothesis to a vectored virus. J Natl Cancer Inst 42:19-28, 1969

34. Manolova Y, Manolov G, Keller J, Levan A, Klein G: Genesis of the 14q+ marker in Burkitt's lymphoma. Hereditas 90:5-10, 1979

35. Klein G: Specific chromosomal translocations and the genesis of B-cell derived tumors in mice and man. Cell 32:311-315, 1983

36. Erikson J, Ar-Rushdi A, Drwinga HL, Nowell PC, Croce CM: Transcriptional activation of the translocated c-myc oncogene in Burkitt's lymphoma. Proc Natl Acad Sci USA 80:820-824, 1983

37. Maguire RT, Robins TS, Thorgeirsson SS, Heilman CA: Expression of cellular myc and mos genes in undifferentiated B cell lymphomas of Burkitt and non-Burkitt types. Proc Natl Acad Sci USA 80:1947-1950, 1983

38. Land H, Parada LF, Weinberg RA: Tumorigenic conversion of primary embryo fibroblasts requires at least two cooperating oncogenes. Nature 304:596-602, 1983

39. Hanto DW, Frizzera G, Gaji-Peczalska KJ, Sakamoto K, Purtilo DT, Balfour HH Jr, Simmons RL, Najarian JS: Epstein-Barr virus-induced $\mathrm{B}$-cell lymphoma after renal transplantation. $\mathrm{N}$ Engl .J Med 306:913-918, 1980

40. Brichacek B, Suchankova A, Hirsch I, Sibl O, Rezacova D, Zavadova $H$, Vonka V: Presence of Epstein-Barr virus DNA in tonsillar tissues. Acta Virol 25:361-370, 1981

41. Ito Y, Kishishita M, Yanase S, Harayama T: Epstein-Barr virusactivating principles in medicinal plants, Herpesvirus: Clinical, Pharmacological and Basic Aspects. Edited by H Shiota, YC Cheng, WH Prusoff. Amsterdam, Excerpta Medica, 1981

42. Zeng Y, Zhong JM, Mo YK, Miao XC: Epstein-Barr virus early antigen induction in Raji cells by Chinese medicinal herbs. Intervirology 19:201-204, 1983

43. Zeng Y, Zhang LG, Li HY, Jan MC, Zhang Q, Wu YC, Wang YS, Su GR: Serological mass survey for early detection of nasopharyngeal carcinoma in Wuzhow city, China. Int $J$ Cancer 29:139-141, 1982

44. Gu SY, Wolf H: Study on recombinant DNA of EB virus and phage $\mathrm{m} 13$. I. Establishment and indentification of recombinant nucleic acid (in Chinese). Cancer 2:129-135, 1983 